\title{
Forming of fixing plate in a progressive die
}

\author{
Kształtowanie wytłoczki płytki ustalającej \\ w tłoczniku progresywnym
}

The paper describes the extrusion process of the product in the form of a fixing plate formed in a progressive die. Numerical analysis included selected extrusion cycles. The Simufact Forming software was used to perform finite element calculations. In the course of the simulation, stress distributions and substitute deformations found in semiproduct during selected process cycles, were determined. In addition, strength parameters were determined, which is necessary for the correct extrusion process. Based on numerical calculations, the actual extrusion process was performed in a progressive die. Obtained extrudates were measured using a 3D measuring device. Overlapping models from the scanner and numerical calculations were used to make a real comparison of the resulting dimensional deviations. A high usefulness of the software for designing tools used in plastic processing, has been proved. KEYWORDS: progressive die, FEM

In developing industry, there is a growing share of processes that require limited energy and time, and at the same time generating a minimal amount of waste (this includes, for example, plastic molding technology), which is in line with EU policies for the coming years.

Cold plastic processing allows molding of products that need not be subjected to further mechanical treatment. Examples are sheets formed in the pressing processes and designed for all types of brackets, guards, transmission components, etc. Along with the diffusion of the pressing processes, continuous advances in the construction of tools, i.e. different types of drawing tools, are made. Correspondingly to the needs of increasing productivity of large-scale or mass production, drawing tools are often designed as progressive tools with a construction that combines up to a dozen or so strokes. The higher degree of complexity of the drawing tool construction forces the constructors to conduct research in the field of semi-finished products and finished products of the desired form in subsequent shaping steps [1-3]. The variety of extrusion, embossing, winding, folding operations, etc., combined with the

\footnotetext{
* Mgr inż. Jarosław Świtacz, dr hab. inż. Jarosław Bartnicki (j.bartnicki@pollub.pl) - Katedra Komputerowego Modelowania i Technologii Obróbki Plastycznej, Politechnika Lubelska
}

increasingly complex shapes of the products, raises a number of structural concerns, particularly regarding the behavior of material under the load. Technological difficulties also arise from the imposition of increasingly narrow dimensional tolerances, which are verified during rigorous technical acceptance of manufactured products. Consequently, it is natural to use numerical simulations to construct complex extrusion tools [1-5].

There are several packages of commercial software designed for numerical simulation with finite element method (FEM). Due to the FEM, it can be possible to simulate the work of a tool and shaping of the product, so that any errors can be detected even at the construction stage, not just during tooling. This also results in a possible reduction of instrument adaptation costs under the assumed optimization.

For the analysis of the pressing process, the authors decided to simulate in the Simufact Forming software, which allows to generate a grid of surface elements that accurately reproduces the assumed shape of the blank and the resulting extrudate [6-10].

\section{Construction of the analyzed drawing tool}

The progressive drawing tool shown in figs. 1-3, intended for pressing the fixing plate consists of 12 strokes. In fig. 3 and in the upper part of fig. 1, there are visible: stamps, clamp plates, shorting bars, guide parts (pillars and guide sleeves) as well as plates and clamps.

In the lower part of fig. 1 and fig. 2, there are visible: matrices, lifting and guide elements, hooks, fixing elements, guide bushes, shorts and plates. Between the lower and upper part of the device shown in fig. 1, there is a strip of metal sheet, which is shown in fig. 4 .

Division of the drawing tool into individual strokes:

- stroke 1 -punching for pilots,

- strokes 2-4 - trimming strokes,

- stroke 5 - bending down,

- stroke 6 - empty stroke,

- stroke 7 - roll up the edges,

- stroke 8 - additional pressing as calibration of shape,

- stroke 9 - empty stroke,

- stroke 10 - trimming and punching,

- stroke 11 - punching,

- stroke 12 - cutting off. 


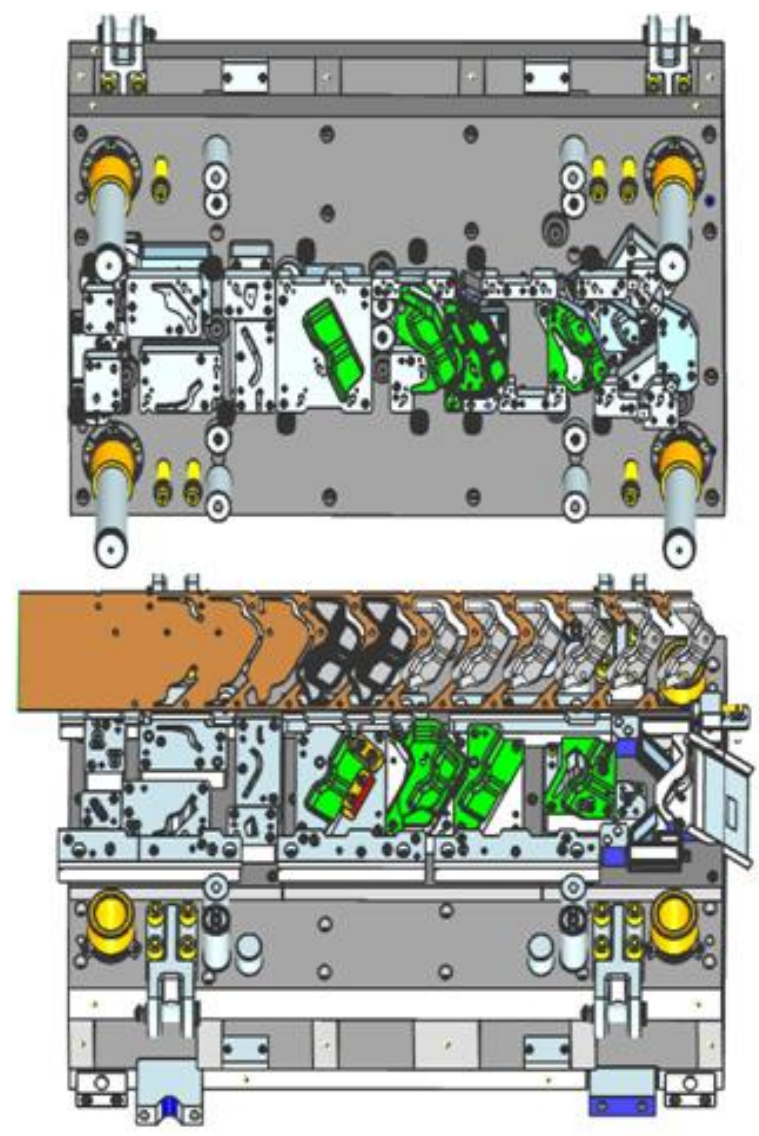

Fig. 1. Progressive drawing tool - demonstration model

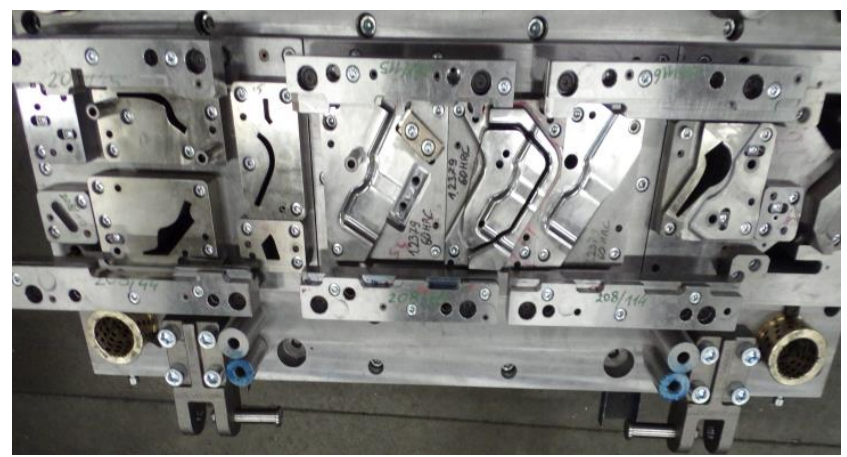

Fig. 2. Lower part of the drawing tool with visible guide bars

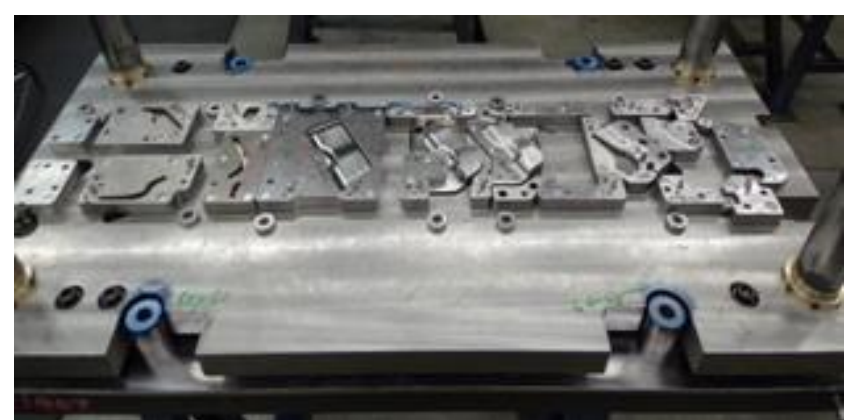

Fig. 3. Upper part of the drawing tool with visible stamps and raised clamp

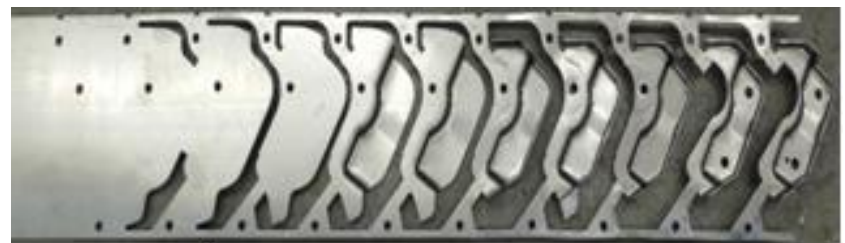

Fig. 4. Top view of metal sheet strip with extruding after subsequent operations

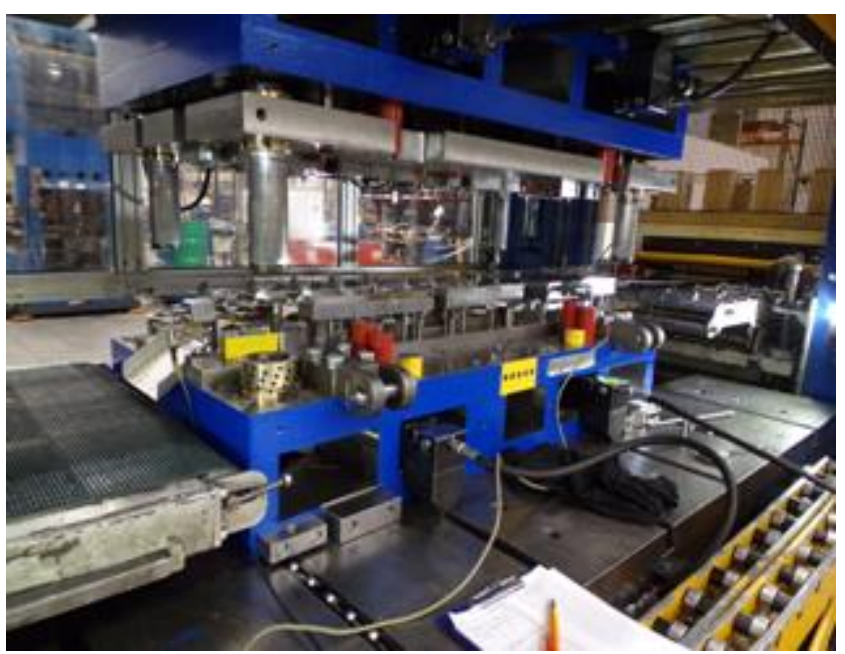

Fig. 5. View of the drawing tool built in crank press with additional equipment

At the design stage, potential dangers of dimensional deviations and shape of resulting blanks were identified and strokes 5, 7 and 10 were chosen for numerical simulation.

The drawing tool was designed in the NX10 program, mainly in its Progressive Die Wizard module designed for the progressive drawing tool design. This tool supports the design of drawing tools and development of plates in the individual strokes, creating so-called layout, i.e. a strip of metal sheet with a die shape in each stroke. Patterns of extrudate in each stroke were used to create models of shaping and trimming tools. The models were prepared for simulation in NX software and exported to STL format.

\section{Numerical analysis}

The purpose of numerical simulations was to verify the assumed design assumptions in order to obtain the assumed shape of the blanks in the pressing process. Fig. 6 shows examples of computational models imported into the Simufact Forming software environment, while fig. 7 shows the distribution of substitute stresses calculated at the end of shaping in the 5 stroke.

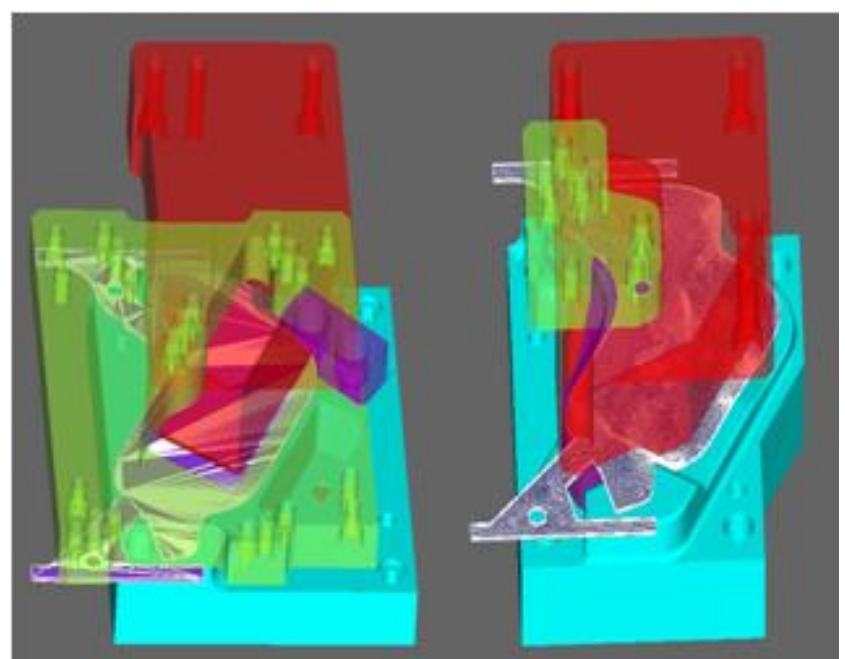

Fig. 6. Numeric models for stroke 5 (left) and stroke 7 (right)

The results of numerical calculations for the subsequent stages of the drawing tool design were 
compared with the theoretical outline of the semi-finished products. In fig. 8, selected results for strokes 5 and 7 are shown. The differences in obtained shapes of the resulting element can be seen. On this basis, the structure of the die was changed, which reduced the observed deviations of the shape.

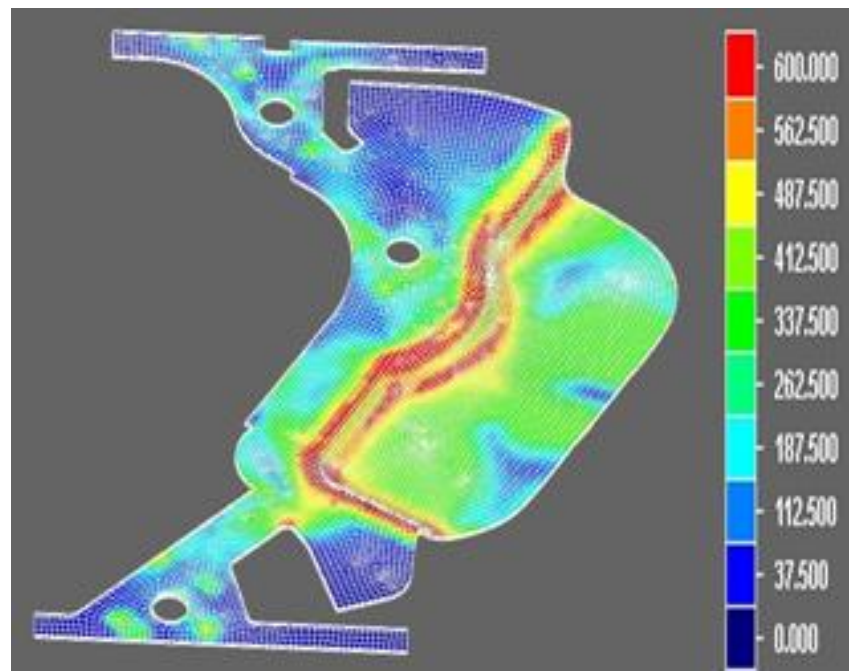

Fig. 7. Distribution of substitutional stresses (in MPa) at the end of the stroke 5

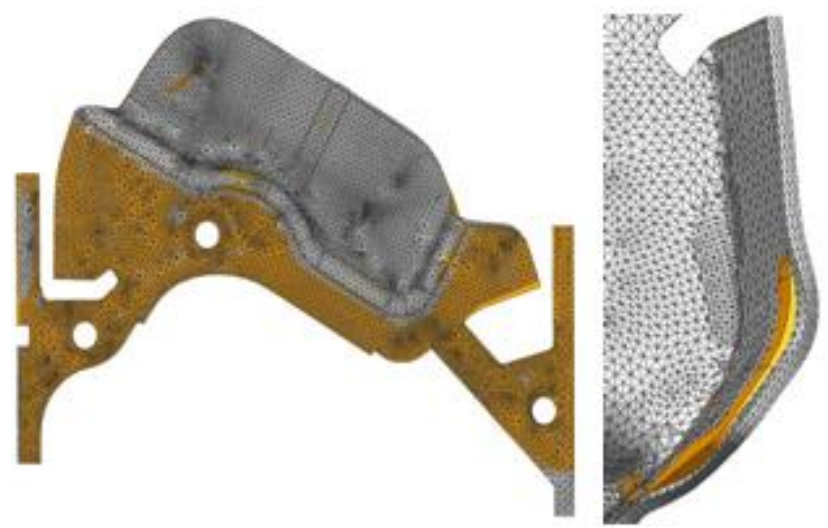

Fig. 8. Overlapping theoretical outlines and obtained in numerical calculations for stroke 5 (left) and for stroke 7 (right)

Obtained differences in the shape of the products in strokes 5 and 7 indicated the need for structural modifications in the tools. It was, however, necessary to take the shape of the blank in the earlier strokes, because during bending in stroke 5 , there was a slight elongation. The differences in simulation were $0.1 \mathrm{~mm}$ to $4.8 \mathrm{~mm}$. In order to improve the quality of the products, it was decided to add guiding bars and additional pilots [79]. This solution reduced torque and contributed to a dramatic improvement in design accuracy according to constructional assumptions.

\section{Experimental results}

As part of the experimental research, the material was analyzed after the first structural changes, when it was possible to verify the correctness of the numerical results. The modifications introduced have contributed to the gradual reduction of dimensional deviations and the achievement of the assumed dimensional tolerances and repeatability of the shape of extrudates. Fig. 9 shows the coordinate measuring machine working space during the measurements of dimensional displacement of the extrudate.

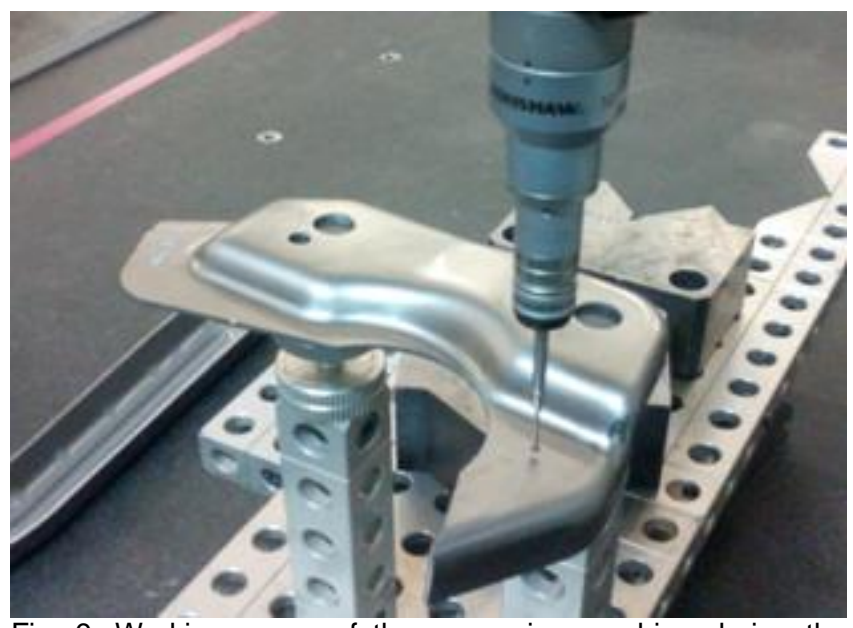

Fig. 9. Working space of the measuring machine during the measurements of dimensional displacement of the extrudate

Fig. 10 shows the initial and final measurement results of the obtained product. Initial dimensional deviations, marked in yellow and red, do not fall within the tolerance range of the product. After introducing structural changes, products that were fully compliant with accepted assumptions were started to produce. After the final design changes were made in the drawing tool, it was re-measured on a coordinate measuring machine. The embossing surface was within a tolerance of \pm 0.2 $\mathrm{mm}$.
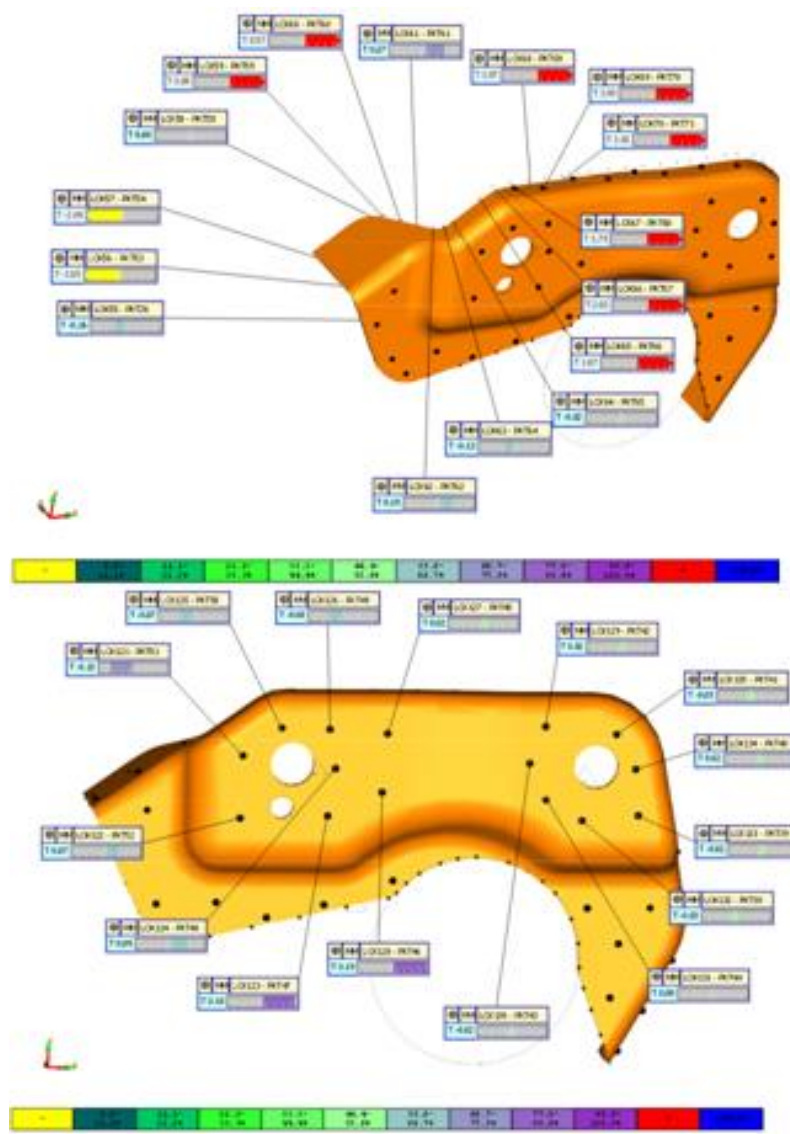

Fig. 10. Results of measurement of the final product tolerance before modification (top) and after modification (bottom) deviation of exceeding the upper deviation was indicated red and exceeding the lower deviation yellow 


\section{Conclusions}

At the stage of constructing a relatively complex progressive drawing tool, a modern FEM simulation tool was used, resulting in a significant reduction in test phase and modifications to achieve the assumed die shape. The proposed solution can be an implementation example for the practical use of CAx tools in the design of plastic forming processes of metal sheet products.

\section{REFERENCES}

1. Marciniak Z. „Konstrukcja tłoczników”. Warszawa: Ośrodek Techniczny A. Marciniak Sp. z 0.0., 2002.

2. Markiewicz E., Wajda F. „Album konstrukcji tłoczników”. Warszawa: Wydawnictwo Naukowo-Techniczne, 1974.

3. Romanowski W.P. „Poradnik obróbki plastycznej na zimno”. Warszawa: Wydawnictwo Naukowo-Techniczne, 1976.

4. Romanowski W.P. "Tłoczenie na zimno". Warszawa: Wydawnictwo Naukowo-Techniczne, 1974.

5. Praca zbiorowa. „Konstrukcja tłoczników”. Warszawa: Państwowe Wydawnictwo Techniczne, 1960.

6. Pater Z., Samołyk G. „Podstawy technologii obróbki plastycznej metall". Lublin: Wydawnictwo Politechniki Lubelskiej, 2013.

7. Paquin J.R., Crowley R.E. "Die Design Fundamentals". Second edition. NY: Industrial Press Inc., 1987, s. 244.

8. Küttner R., Nekrassov G. "Development of an intelligent integrated environment for computer aided design of work holders". Proceedings NordDesign 2002, ed. Per Boelskifte \& Johannes B.Sigurjonsson, August 14-16 2002 NTNU, Trondheim, Norway, s. 185-193.

9. "Progressive Die Wizard Help", EDS 2003.

10. Stadnicki J., Wróbel I. "Application of optimisation in designing of stamping die for car body parts". Mechanik. 7 (2015). 